This is the author's version of a work that was published in the following source:

Paetz, A.-G.; Dütschke, E.; Fichtner, W. (2012).

Smart Homes as a Means to Sustainable Energy Consumption: A Study of

Consumer Perceptions $\square$.

Journal of consumer policy, 35 (1), 23-41.

doi:10.1007/s10603-011-9177-2 뜸

Please note: Copyright is owned by the author(s) and / or the publisher. The commercial use of this copy is not allowed. 


\title{
Smart Homes as a Means to Sustainable Energy Consumption: A Study of Consumer Perceptions
}

\author{
Alexandra-Gwyn Paetz \& Elisabeth Dütschke \\ \& Wolf Fichtner
}

\begin{abstract}
European and national policies are aimed at reducing greenhouse gases and increasing energy efficiency-also in the household sector. For this purpose, new solutions for private homes based on information and communication technologies (ICT) are being developed and tested. However, up to now, hardly anyone has seen, experienced or lived in an environment that offers the full range of ICT-based energy management solutions. In this study, consumer reactions to a fully furnished and equipped smart home are analysed using focus groups (four groups with a total of 29 participants). The analysis looks at consumer perceptions of and reactions to an energy management system which optimizes electricity consumption based on different ICT solutions. The topics that were demonstrated in practice and then discussed with the participants included variable tariffs, smart metering, smart appliances, and home automation. In general, there were positive group reactions to the smart home environment. Consumers saw many advantages for themselves; especially the chance to save money. However, giving up high levels of flexibility and adapting everyday routines to fit in with electricity tariffs were regarded as difficult. Smart appliances and smart meters were therefore considered to be necessary elements by most participants. Concerns regarding data privacy played a major role in one of the groups.
\end{abstract}

Keywords Sustainable consumption * Smart home * Smart energy management * Consumer perception $*$ Focus groups

As greenhouse gases (GHG) contribute to global warming, European and national policies are aiming to reduce them. The German government has set the target to become a low-

\author{
A.-G. Paetz $\left(^{*}\right)$ W. Fichtner \\ Chair of Energy Economics, Karlsruhe Institute of Technology (KIT), Hertzstr 16, \\ D-76187 Karlsruhe, Germany \\ e-mail: alexandra-gwyn.paetz@kit.edu \\ E. Dütschke \\ Fraunhofer Institute for Systems and Innovation Research (ISI), Breslauer Str 48, \\ D-76139 Karlsruhe, Germany
}


carbon society and to reduce the GHG emission in Germany by $80 \%$ until 2050 (BMWi 2011). This is only possible if large changes take place in the energy, transport and household sectors, as these are all major emitters of GHG in Germany (UBA 2011). To meet these targets, the main issues being discussed include expanding the supply of renewable energy (to 35\% by 2020 in Germany) and increasing energy efficiency. This will have important implications for power generation and consumption, as renewable resources tend to fluctuate and as in the case of sun and wind are neither controllable nor fully predictable. Thus, it will be necessary to enable the electricity system to adapt to these new conditions. The system will need to react quickly to critical grid situations, e.g., to meet high electricity demand in times with insufficient renewable supply and conversely to also be able to handle high renewable generation, e.g., on windy days. The currently discussed measures include metering actual consumption more precisely (e.g., in real-time) and shifting loads so that consumption matches the current supply of electricity more closely, i.e., to adapt demand to actual supply instead of the other way around. This more sustainable electricity system, which is built on greater energy efficiency and a high share of renewable energy, will have two major impacts on private households: In order to increase energy efficiency, consumers will need to decrease their electricity consumption and may thus need to make investments, e.g., in more efficient appliances. Furthermore, they will be required to shift loads, which may also involve adaptations of everyday behaviour and routines, e.g., doing the washing at a different time of the day. However, promoting the sustainable use of electricity is often regarded as particularly difficult, because electricity differs significantly from other consumer goods: It is invisible, untouchable, and only consumed indirectly via related activities, such as working with a computer (Fischer 2007; Grønhøj and Thøgersen 2011; Hargreaves et al. 2010).

The measures being discussed to influence the electricity demand of private households include variable electricity tariffs, smart metering, smart appliances and home automation, and in an ideal case, a combination of all these elements. We define the combination of all these elements as a smart home scenario. ${ }^{1}$ Variable electricity tariffs mean that the price to be paid per kilowatt-hour ( $\mathrm{kWh}$ ) varies according to the balance between supply and demand. A relatively simple and well-known variable tariff is a day- and night-tariff, where consumers pay a lower price at night when the demand for electricity is lower than during the daytime. This tariff was created to match the supply of electricity produced by nuclear and coal power plants which deliver a constant supply of electricity throughout day and night. In the context of renewables, if consumption is to be influenced by changing price levels, a variable electricity tariff could include several price changes per day which are adapted to the fluctuating supply of power. Smart meters record electricity consumption digitally and thereby offer more detailed information about actual consumption in real-time or at least within minutes for both the consumer and the utility, if a telecommunication link is provided. This information can be displayed in various ways, e.g., on in-house displays, smartphones, or web portals. Based on variable tariffs and smart meters, more advanced ICT solutions (information and communication technology) are currently being developed, which enable automatic adjustments of energy demand. Smart appliances are one example of these. A smart appliance is an electrical household device able to react

\footnotetext{
1 The term "smart home" is generally used for linking separate devices of a household to a network and can therefore include aspects of ambient living, entertainment, and security. In our research we focus on aspects of energy management.
} 
automatically to external signals, e.g., turning itself following a signal from the electricity grid. These external signals can be price signals (i.e., variable tariff) or other signals sent by the utility depending on the current power supply and grid situation. In practice this could mean that the dishwasher turns on automatically when receiving the signal that the electricity price is low now and for the next hour. This could support consumers in adapting their consumption to supply with little or no decrease in comfort. The elements described so far can be further embedded in a system of home automation that constantly monitors consumption (smart metering) and plans the optimal use of devices (smart appliances) according to the forecasted electricity prices (variable tariffs). The control of such a home automation system can be handed over to a third party (e.g., demand-side manager).

Some of these measures have been addressed in European and national policies. On a European level, new conditions for private households have been enforced in the directive 2006/32/EC, which requires Member States to introduce, among others things, some kind of instrument or meter that provides feedback to private households on energy consumption and information about energy efficiency. This directive has been transformed into national law also in Germany ( $\$ 40$ Energy Act) and prescribes that energy suppliers have to offer some kind of electricity tariff that motivates private consumers to conserve energy and/or shift their electricity consumption from peak to off-peak periods. So far about 100 utilities in Germany comply with this law (Energate 2011).

The roll-out of smart metering has started throughout Europe. Current estimations of present and future investments in smart metering in the European Union present figures as high as 51 billion euros (Faruqui et al. 2010). In Germany, new buildings have had to feature smart meters since January 2010, if technically and economically feasible $(\$ 21 \mathrm{~g}$ Energy Act). However, the number of households that are actually equipped with a smart meter is still very low. While smart metering devices are already available to some extent, many utilities are still working on the development of accompanying products, such as internet platforms that allow household electricity demand to be monitored in a comfortable way.

Smart household appliances are increasingly being offered on the market accompanied by field tests of smart metering devices. However, complete solutions which also include home automation have not been offered on the market up to now (cf. also Fischer 2007). Thus, hardly anyone has seen or experienced the combination of all these components, which are supposed to contribute to a more energy-efficient and sustainable lifestyle. However, if homes are turned into "smart" homes, this will have major impacts on consumers: On the one hand, significant investments will be necessary, and, on the other hand, if the smart home is to work effectively towards the goals of energy efficiency and load-shifting, consumers will have to make changes to their everyday behaviour and routines. This second issue is the focus of this paper: What do consumers think about this kind of smart home?

To answer this question, we analysed consumers' perceptions and evaluations of the elements of a smart home environment, which have already been introduced: variable tariffs, smart metering, smart appliances, and home automation. For this analysis, we used a unique environment-a fully furnished and operative smart home, developed and built in 2010 by the Karlsruhe Institute of Technology (KIT). The smart home is part of the MeRegioMobil (Minimum Emissions Region and Mobility) research project, which aims to find ICT-based solutions to the challenges of an energy system with a higher share of renewable energy on the supply side and larger consumers (in form of battery electric 
vehicles) on the consumption side. Besides the development of the smart components and their techno-economic analysis, the user acceptance of these smart technologies is also evaluated within the project.

In the following, we summarize the state of knowledge in the relevant literature and outline our research questions in more detail. The next section presents our methodology including a short description of the smart home environment. In this study, four focus groups with a total of 29 participants experienced the smart home environment and discussed their perceptions in a moderated group discussion. The results from the groups are presented and the paper closes with a discussion of the results, points out the limitations of the current study, and presents the conclusions and policy recommendations.

\section{State of Research and Research Questions}

\section{Previous research}

As smart homes and the related technologies and products are not yet widely available on the market, there are only a few publications on research that include first-hand consumer experiences with fully equipped smart homes. However, there are some papers on the different technologies which constitute a smart home environment, e.g., on smart metering, variable tariffs as well as the use of displays and other features to support electricity monitoring and conserving (Fischer 2007). This section presents a brief review of this literature.

Using smart meters, real-time feedback, or variable tariffs to influence energy use by private consumers is not a new idea. For example, Heberlein and Warriner (1983) published a study in 1983 in which consumers were confronted with varying time-of-day price ratios. However, research interest in this topic has recently risen again due to the political developments referred to in the introduction, technology developments, and climate change concerns.

Utility companies around the world have introduced variable tariffs, often in combination with smart meter trials which enable consumers to monitor their consumption without any delay, in order to learn about these effects: The results indicate that energy reductions of between 5\% and 25\% are possible (Darby 2010; Schleich et al. 2011; SF 2008). Other studies paint a less optimistic picture with regard to savings resulting from real-time feedback available from smart meters and accompanying devices: For example, Allen and Janda (2006) conducted a study which included real-time energy data feedback using a digital electricity monitor, which was tried out by 10 households over a period of several months. While there was increased awareness among the households, the actual effects on electricity consumption were marginal to non-existent (see also Pyrko 2011 for similar results).

Even if energy consumption is reduced, the sustainability of this effect over time is a topic that is often discussed. In a study by Van Dam et al. (2010), participants using home energy monitors were initially able to reduce their consumption by $7.8 \%$, but were not able to maintain this reduction over a period of 15 months.

These kinds of technologies are thought to contribute to demand reduction primarily based on an information deficit model (cf. Hargreaves et al., 2010): It is assumed that consumers lack awareness and knowledge of their electricity consumption due to its "invisibility" (Fischer 2007; Hargreaves et al. 2010). Introducing some kind of technical system to make electricity use more visible should therefore encourage consumers to reduce 
consumption. Research on feedback on electricity consumption in general seems to support this assumption (Darby 2010; Grønhøj and Thøgersen 2011). However, as outlined above, it is not yet clear whether these measures will lead to the expected results; moreover, although providing information and feedback is a precondition, it may not be sufficient on its own.

Another question that has not been answered so far is whether consumers are interested and willing to make use of the innovative technologies going to be available soon. While research has up to now mostly focused on the possible effects on electricity consumption, a more detailed analysis of consumers' attitudes and expectations towards these technologies is also necessary.

An extensive study by forsa (2010) conducted on behalf of the Verbraucherzentrale Bundesverband e.V., the leading consumer association in Germany, analysed the perceptions and evaluations of smart metering in Germany. An initial focus group study showed that consumers' knowledge of smart metering is low. For example, none of the focus group participants had heard of the English expression "smart meter"-which is often used by German energy experts. In a follow-up survey using a sample of $n>1,000$ participants only $3 \%$ knew the real meaning of the term. The German terms "intelligenter" or "neuer" (=new) meter were slightly more familiar in both studies, but still a vast majority had not heard of them. After a short explanation of the concept of smart metering, there were positive initial reactions from participants of both the focus group and the survey. Participants in both studies saw the advantage of having the chance to reduce spending on electricity and exercise a greater control of costs; however, there were also strong doubts about the real potential for conserving electricity and saving costs as well as major concerns about the necessary investments and possible misuse of data. The possibility that home automation could be a future feature in addition to the smart meter was also welcomed by participants hoping for more convenient household management, but fears were expressed about the time and effort required.

Home automation was also discussed with participants of a study by IBM (2007). In this study, consumers stated they would be willing to reschedule certain household activities to off-peak periods_-such as turning on the dishwasher-but there were objections to having to modify cooking habits or using entertainment appliances. In-depth interviews as part of the Intelliekon-project showed different results (Birzle-Harder et al. 2008): Consumers claimed that nearly all of their household activities took place within a narrow time frame and could not be rescheduled.

Mert et al. (2009) analysed consumer attitudes towards different load-shifting options in relation to household appliances including home automation scenarios. They found a relatively high acceptance of these ideas in general. Significant financial benefits turned out to be the main motivator; environmental benefits were seen as positive side-effects and consumers also emphasized the importance that the adoption of these options should not be linked to any reduction in comfort.

To sum up, the current literature indicates that smart home technologies do have the potential to support the reduction of energy consumption in private households. However, researchers have found different effect ranges including zero reduction of energy consumption. Results with regard to load-shifting behaviour point in a similar direction. Regarding consumer perceptions and acceptance, the studies published so far indicate that consumers usually are positive if confronted with smart home related technologies. On a general level, however, knowledge and awareness seems to be limited. The main driver for the adoption of such technologies seems to be the potential cost-saving involved (see also Hargreaves et al. 2010), but consumers also anticipate several disadvantages. 
The literature review shows that there is still very little research on consumer perceptions regarding smart home technology. Thus, this study takes an exploratory approach to this issue. The focus here is on consumers' first reactions to the full range of technologies demonstrated within a smart home environment. What is the general reaction to the full future scenario presented? How are the different elements, i.e., variable tariffs, smart metering, smart appliances, and home automation, perceived? How realistic is their integration into a household's everyday life in the near future? What barriers need to be overcome? Can these technologies lead to a more efficient use of electricity from a consumers' point of view? And how will marketable products have to be designed to be successful?

\section{Method}

\section{Research design}

In order to answer the research questions outlined above, we chose an exploratory design based on focus groups. Focus groups are a method to elicit and explore opinions and are therefore especially useful if individuals are confronted with innovative products or ideas: On the one hand, focus groups allow for a close interaction with the researcher and the technology; on the other hand, participants have the possibility to ask questions and also to stimulate each other in evoking associations and perceptions to discuss them as a group. Focus groups thereby offer the chance for the researcher to develop a deep understanding of why people feel the way they do by analysing their verbal and non-verbal reactions (Bryman 2001). Due to group dynamics, issues are often raised that probably would not have come up in individual interviews. Thus, a rich amount of data can be collected in the participants' own words.

Obviously, it is not possible to provide conclusions that are representative for a larger population using focus groups, or to make precise quantitative predictions about the development of a certain product. The outcomes of a focus group study depend strongly on those persons taking part-thus selecting participants is an important step. Additionally, each group develops specific dynamics-so it is usually advisable to conduct more than one focus group.

To complement the focus group discussions, short standardized questionnaires were handed out before and after (pre- and post-questionnaire) the actual discussion in order to obtain additional information about each participant's individual views. The pre-questionnaire included socio-demographic information, items on attitudes towards technological innovation and the environment as well as electricity-conserving behaviour. The post-questionnaire included questions about general evaluations of the smart home, its technologies as well as about price expectations that drew on the price sensitivity meter (PSM). PSM is a method for surveying prices for emerging products from a customer's point of view, which in this case was used as a basis for detecting optimum cost savings generated by variable electricity tariffs (Bergstein and Estelani 2002; van Westendorp 1976).

\section{Sample}

Twenty-nine individuals attended one of four focus groups which all followed the same design and lasted between 2.5 and $3 \mathrm{~h}$. This included the pre-post-questionnaire and a 
sequence of short presentations or scenario demonstrations given by the moderator, followed by extensive group discussions based on a guideline of specific questions.

The size of groups varied between six and nine individuals. All groups included women and men, but overall men were in the majority (18 out of 29). Participants were relatively young on average as the first two groups consisted of students while the third group included students and "average adults" (=non-students) from the Karlsruhe area; the last group consisted of non-students only. The age of the participants varied between 21 and 61 years; 21 individuals including all the participating students were younger than 30 years.

Recruiting student groups was motivated by the following reasons: First, students were regarded as one of the main target groups for actually living in a smart home environment in the future, as they usually do not already have fully equipped homes and the technologies will probably be available on the market when they start investing in such equipment. Second, as the KIT is a university with a strong technological focus, it was expected that students would be relatively open-minded to the technologies presented. Third, it was assumed that students have not yet developed fixed habits for everyday life with regard to managing a household and would therefore be more flexible about choosing, e.g., a variable tariff. Thus, students constitute an interesting, albeit specialized group. Therefore, the two additional groups mainly consisted of individuals over 25 who are already established with regard to household and profession. For these groups, recruitment aimed at creating heterogeneous groups with regard to profession, age, social background, e.g., level of education, and living situation, e.g., size of households and house-ownership.

Participants were recruited in various ways including mailing lists of universities, newspaper ads and distributing flyers, and they were selected using a screening questionnaire that covered the aspects just mentioned. Participants received a small fee (30 euros) after the group discussion.

Nineteen participants were students. Of the 10 non-student participants, seven were employed or self-employed in fields including cosmetics, healthcare and the energy industry. Three were either unemployed or retired. Four participants stated that they lived alone; nine lived together with partners or family, and 16-all of them students-lived in shared accommodation. The household size varied between one and 15 individuals. Four participants currently had children still living at home.

In the pre-questionnaire, participants were asked to indicate which two out of five topics are the most important challenges of our time. Most participants thought that environmental problems were the most important challenge of today followed by the economy. Health care, unemployment, and crime were rated as less important. Students and non-students did not have different opinions here; neither did the four groups differ significantly from each other. Another question was whether people liked to try out technological innovations. None of the participants chose the option "I prefer to stick to approved technologies." While seven of the students indicated "I prefer to wait until others have gained some experience with it," the remaining 12 as well as all of the non-students participants ticked "I like to try them." Thus, in sum, participants rated themselves as being environmentally aware and very open to innovations in general with students being a bit less open. The questionnaire also included some six-point-Likert-scaled items on energy conserving in everyday life (cf. Fig. 1). On these items, participants described themselves as striving to conserve energy in daily life with students indicating a significantly higher level of effort. Moreover, students also expected a higher impact on daily comfort through energy conserving measures. In general, participants disagreed with the statement that private consumers only have few possibilities to conserve, and did agree that conserving energy implies changing your lifestyle. 


\section{To conserve energy it is required to change one's lifestyle.}

\section{A private household cannot contribute much to conserve energy.}

\section{Protecting the environment and conserving energy has an impact on daily comfort.}

\section{At home we strive to conserve energy.}

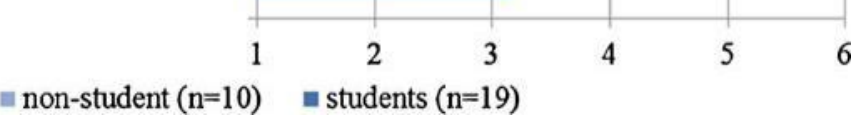

Fig. 1 Mean ratings of participants on items concerning energy conserving; $n=29 ; 1=I$ do not agree at all, $6=I$ absolutely agree

Smart home setting and procedure

The KIT has set up a fully furnished $60 \mathrm{~m}^{2}$ smart home, which consists of two bedrooms, a living room, a bathroom, and a kitchen (cf. Fig. 2). The kitchen is equipped with smart appliances that are able to receive communication signals and provide extensive information on their operating state, such as the remaining time of the dishwasher's current programme. The rooms are air-conditioned with a cooling ceiling system. Furthermore, photovoltaic modules (PV) and a micro combined heat and power plant $(\mu \mathrm{CHP})$ can generate electrical power in the smart home, but they were not core aspects for the present focus group study.

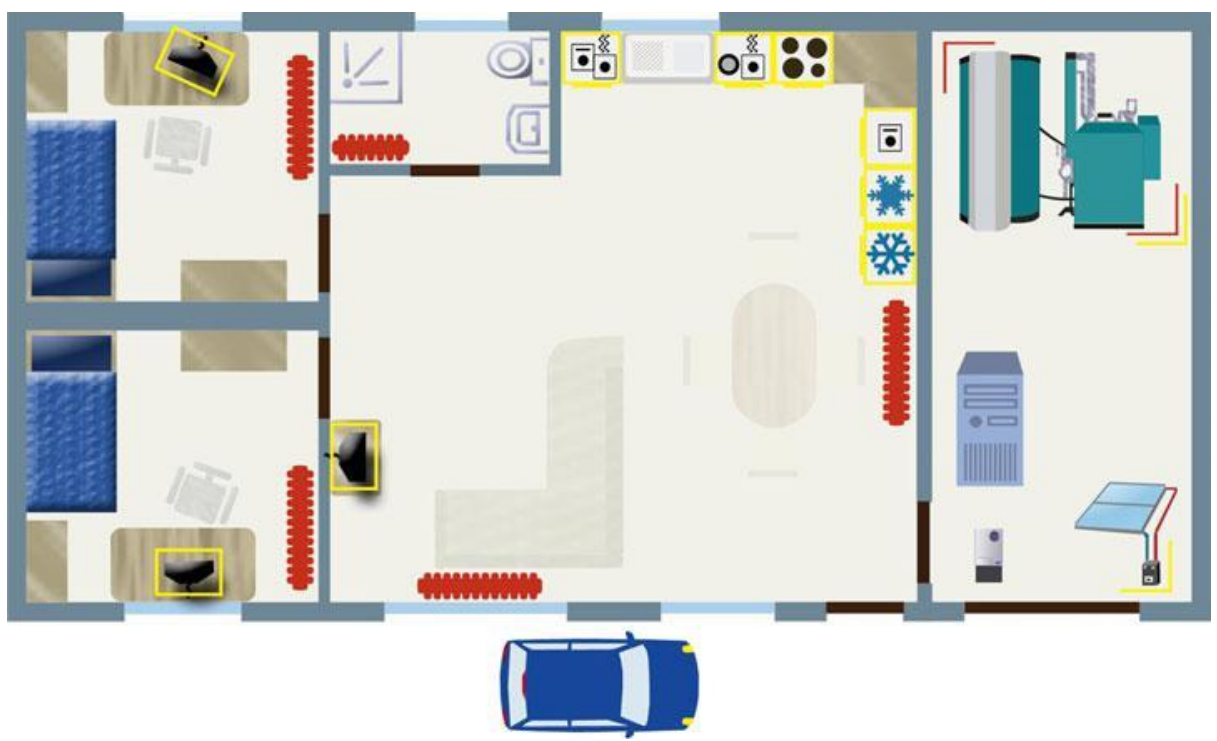

Fig. 2 Sketch of the smart home layout on KIT's campus 
All data about electric power generation and consumption in the house is monitored and collected in a central control box which functions as an energy management system (EMS). The EMS can schedule the operating time of each appliance according to external (price) signals and maximize the consumption of the internally-generated power. It is possible to specify preferences in the EMS, such as the time by which the dishwasher should be ready, in order to provide flexibility and convenience. All rooms are equipped with energy management panels (EMP) in the form of touch screen displays, which enable interaction between residents and the EMS. The overall state of the smart home, such as the level of electricity consumption and generation, can be visualized on each EMP and residents are able to enter their individual preferences.

The group discussions took place in the living room including the open kitchen of the smart home and were moderated by the first author assisted by the second author. When participants arrived, they were given the pre-questionnaire. The group discussion then started by collecting associations about electricity and current electricity use at home. Afterwards, the various technologies implemented in the smart home were discussed. Making full use of the research design, various audio-visual channels of communication were used to introduce each technology: verbal explanations (of all technologies), printed information on hand-outs (variable tariffs), presentations on a wide screen (variable tariff, home automation) and scenario demonstrations (smart meter and smart appliances). Electricity tariffs were the first topic, starting with standard tariffs and continuing with time-of-use tariffs, and load-dynamic tariffs. A variety of complex tariffs were also introduced to the participants in order to extend the state of knowledge of other field studies that have so far mainly tested simple structured tariffs. Two different time-of-use tariffs were developed: a simple one with two different time zones and price levels (day and night at 22 and $19 \mathrm{ct} / \mathrm{kWh}$, respectively ${ }^{2}$ ) and a more complex one with three different price levels $(15,20$, and $25 \mathrm{ct} / \mathrm{kWh})$ that can change hourly (i.e., a maximum of 24 time zones per day) with a daily forecast for the next $24 \mathrm{~h}$. Another tariff with two price levels (19 and $25 \mathrm{ct} / \mathrm{kWh}$ ) depending on the current house-load (below or above $1.2 \mathrm{~kW}$ ) was introduced as a load-dynamic tariff (cf. Fig. 3). As a last option, a tariff with consumption zones was discussed in which the price rises by $3 \mathrm{ct} / \mathrm{kWh}$ after every $1,000 \mathrm{kWh}$ (starting from $16 \mathrm{ct} / \mathrm{kWh}$ ) for the next $1,000 \mathrm{kWh}$ (based on annual consumption). After tariffs, smart meters were introduced and their attributes demonstrated by showing the actual smart meter of the smart home as well as additional applications, e.g., real-time load curves visualized as graphs on a screen, and were then discussed by the participants. Next, smart appliances from the smart home kitchen were shown and, as an example, it was demonstrated how the dishwasher automatically started its programme based on electricity price information. The last feature presented and discussed with the groups was the full automation of the smart home, meaning that the communication infrastructure receives/sends certain signals from/to the smart appliances such as "turn on" (cf. EMS). The group sessions closed with a final round during which participants were required to make an individual final evaluation of the elements presented. The post-questionnaire was distributed at the end.

\section{Data analysis}

The group discussions were recorded and transcribed literally (Kuckartz et al. 2007). Using the qualitative content analysis method by Mayring (2000), the transcripts were then coded following a preliminary code manual, which was developed based on the focus group

\footnotetext{
${ }^{2}$ The average unit charge for residential customers is around $22 \mathrm{ct} / \mathrm{kWh}$ in Germany.
} 


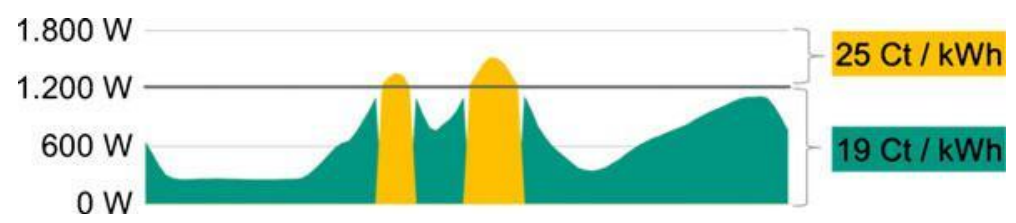

Fig. 3 Example for a load-dynamic tariff exemplified with a $24 \mathrm{~h}$ load pattern of an exemplary household

guideline. This manual was further refined during the coding of two of the groups and repeatedly discussed between the first two authors of this paper. Once the final code structure had been agreed upon, all the groups were re-coded in accordance with it. Final codes referamongst others-to the technology currently discussed, behavioural intentions and attitudes towards the technology, motives expressed, and specific suggestions in relation to the technology. In order to ensure coherent understanding and application of the code manual, the first author coded all four groups while the second author checked the codes of two groups. Only minor disagreements were revealed by this process.

In the following section, the results of all the focus groups are presented and illustrated using participants' statements. All the statements have been translated into English while retaining the gist of the original German. Every participant was given a number during the anonymization process. The digits after each quote refer to the participant and his/her focus group, e.g., P1-1, male, 30 yrs. for participant number one that took part in the first focus group, male, non-student and 30 years old.

\section{Results}

In general, group reactions to the smart home environment were positive. Participants saw many advantages for their own household in using the demonstrated equipment. Numerous benefits were perceived for all the technologies, the most important being monetary savings. The higher the anticipated saving and the shorter the investment payback time for smart home equipment, the better was the participants' evaluation. Variable tariff models were the most popular choice for the near future, as these require no significant investments in hardware. However, forgoing a high degree of flexibility and scheduling everyday life around different electricity prices as in the case of variable tariffs was regarded as difficult. So the main barrier to adopting a new technology seems to be the cognitive effort required for changing patterns of behaviour. In the following section the evaluation of each technology is presented in detail.

\section{Variable tariffs}

Electricity tariffs that vary in price per $\mathrm{kWh}$ were attractive to the majority of participants (22 out of 29 participants); all of them would consider a variable tariff in the near future with a strong preference for time-of-use tariffs. The two main motivations for this positive evaluation were the possibility to save money and conserve electricity. While the monetary incentive was valid for all participants with the exception of one person, the benefit of conserving electricity was mainly seen as a positive side-effect. This is similar to another environmental benefit that was viewed as positive but not essential in the personal decision-making process: the possibility to integrate more renewable energy into the grid.

Obviously I'm thinking also about the environment, but personally my biggest motivation is savings. (P 22-3, male, 47 yrs.) 
For three participants, however, environmental benefits played a key role in the decision for an electricity tariff. They were very much in favour of integrating more renewables into the grid and already used "green" electricity. Their willingness to consider a variable tariff was mainly motivated by the chance to improve their ecological footprint. Another seven participants preferred the load-dynamic tariff to the time-of-use tariff because a load-dynamic tariff would not only motivate a shift in consumption but also encourage electricity conserving since a lower price applies if household consumption remains under a certain threshold $(1.2 \mathrm{~kW}$ in our example-cf. Fig. 3). Interestingly, these environmentally friendly participants mistrusted the energy supplier's calculation of the variable price levels and needed reassuring that the calculation was correct.

Even though I believe that generating electricity from wind is a great concept, I'm not sure whether I can trust those large power companies that they actually supply green energy. ( $P$ 24-4, male, 44 yrs.)

While the non-student participants accepted the general idea that utilities try to find ways to adapt consumption to supply, as in the case of variable tariffs, the students were sceptical. As many students had a good technical grasp of the electricity system, they realized that adapting consumption to renewable supply could be cheaper for a utility company than adapting other generation capacities. Even though this point was discussed in the mixed group, the non-students did not change their opinion-assuming that they could save money with variable tariffs.

When thinking about daily patterns of behaviour, there were doubts about how much of the actual consumption could be shifted in the household. Nobody doubted that it is possible to shift a few predictable activities, such as using the dishwasher or the washing machine, as long as this is still convenient. In the case of time-of-use tariffs this means that the low-priced time zones should not start too late in the evening in order to avoid noise nuisance and related conflicts with other household members or neighbours. This concern was especially expressed by the student participants, who more often lived in multi-storey buildings.

I live in a shared apartment on the 2nd floor and I have neighbours above and below.

I can't regularly start the washing machine at $11 \mathrm{pm}$. (P 9-1, female student, 23 yrs.)

Furthermore, tariffs with long price level validity were preferred to those that change their price schemes, load zones or price levels on a daily basis. Answers from the postquestionnaire showed that a majority of 17 participants (61\%) preferred a price scheme which is fixed for at least a month or longer. Five persons indicated agreement with rates which vary within a day or even shorter periods; six favoured weekly changes.

The reason for preferring a fixed price scheme was univocal: There was a strong feeling that trying to adapt to a variable tariff would mean forgoing high levels of flexibility and being occupied with checking price levels and planning consumption for the next day. Thus, a less dynamic tariff was believed to be more effective as it would be more manageable in everyday life-especially in the long run.

Probably it would be hard for me to change my habits the first time, but-let's say this tariff structure would be valid for 1 year-it would pay off, because I just need to shift certain activities once and it would become natural in the long run. (P 7-1, male, student, 26 yrs.)

With the exception of one participant, nobody believed that coordination with other household members would work in the long run. Thus, the perceived cognitive effort required was the main barrier for all participants when it comes to behavioural change.

I definitely don't want to think about electricity prices every minute and bow to a household plan. (P21-3, male student, 25 yrs.) 
As no monetary savings can be achieved without adapting consumption patterns to the variable tariff, one point of discussion was whether monetary savings are a bigger incentive than the convenience of "consumption-as-usual." The PSM analysis from the post-questionnaire suggests that the point of indifference is at savings of 80 euros per year, meaning that lower savings are perceived as insufficient to change behavioural patterns.

Another much discussed issue was how to offer and design variable tariffs in order to increase their usability and attractiveness. Many ideas concerned the information required for variable tariffs, especially load-dynamic tariffs. Therefore it was suggested, on the one hand, to collect more information, to visualize it, e.g., through a smartphone application, and to be given feedback, especially on the environmental impact of tariffs. On the other hand, participants also suggested supplementary equipment such as automated computer systems that could interpret price information and then either automatically control household appliances or tell residents how to use them the most efficient way.

Some computer unit that can recognize the price level and tell the dishwasher to start during a cheap time slot. That would be great. (P13-2, female student, 24 yrs.)

\section{Smart metering}

As described above, participants desired greater transparency and more feedback, especially in visualizing the impact of their consumption patterns on costs and the environment. All the groups were thrilled by the smart meter that showed the load curve of the smart home in real-time via the internet or on the EMPs.

This is exactly the curve I'm looking for! Really impressive, because now I can see my consumption and electricity is no longer invisible. (P5-1, female student, 27 yrs.)

The first spontaneous reactions were very positive and participants tried to find out how to get the most information out of the smart meter. Apart from two participants who already had detailed knowledge of their own home's electricity consumption, the others anticipated being able to analyse the load at home and discuss it with other household members or even neighbours.

I'd start turning on and off every appliance in order to see its impact on the load curve. Maybe it would be also interesting to borrow some home devices of my neighbour and see whose is more efficient. This nourishes my playing instinct. (P173, female, 51 yrs.)

Even though a few strongly asserted that they would use household appliances more efficiently, because of the constant feedback from the displays, there was a broad consensus that the frequency of looking at the load curve would decrease over time.

After a while I would know more or less how much I consume and if I don't change anything substantially such as replacing a less efficient appliance, there would be no need to look at the load curve regularly. (P26-4, female, 59 yrs.)

In all four groups this initial positive impression decreased over the course of the discussions. By the end, a third of the participants, all of whom were students except two, said that they would not consider the acquisition of a smart meter. Four reasons were given for this:

(1) Especially among the student participants the smart meter was not rated as innovative or helpful enough for their information needs and daily routines: "To me the smart meter is not transparent enough, because it just shows me my total load curve. This 
piece of information on its own is nearly worthless if it is not used for further technical purposes." (P7-1, male student 26 yrs.)

(2) Two participants had concerns about data privacy issues and therefore rejected the technology in principle: "No that's unthinkable to me. That's sensitive information. The utility could easily see whether I'm at home or on holiday." (P24-5, male, 44 yrs.)

(3) One participant rejected the smart meter because of the feeling of not being able to do more for living more energy-efficiently: "I'm hardly at home, I only use the washing machine once a week. What do I need the smart meter for? I will never save enough electricity to payback the cost of the meter." (P17-3, female, 51 yrs.)

(4) While particularly the students living in shared accommodation liked the idea of showing their flatmates unnecessary loads, such as leaving laptops running overnight, they were at the same time not as convinced as the non-students that this would have an educational effect: "One of my roommates is not sensitized to energy at all. He even leaves the fridge open. Generally it would be good to show him how much electricity he is wasting, but I doubt it will help." (P10-3, male student, 23 yrs.)

The price of smart meters was an important issue for those who considered buying one. A realistically acceptable price for non-students falls within a range between 40 euros and 120 euros. However, the expected payback period, i.e., the period of time in which the investment in the smart meter pays for itself due to the savings it achieves was relatively short-rated at just 1 year. In other words: If the investment in a smart meter is higher than the electricity cost savings in 1 year, the interest in purchasing a smart meter is very low. Many even felt that the utility should provide smart meters to everybody for free.

The smart meter doesn't only offer us advantages. The utility benefits the most, because they can buy electricity according to our consumption data and save money in the supply. So why don't they just exchange the meters and we can both benefit from it? (P20-3, male, 57 yrs.)

By the end of the discussion a majority of 20 participants would consider buying a smart meter, but mostly only in combination with a variable tariff in order to have a higher incentive to save money and be more motivated to change daily routines.

\section{Smart appliances}

Household appliances that are able to communicate and react to external signals were perceived as the inevitable future by all the participants, especially when it comes to variable tariffs. On the one hand, smart appliances offer higher levels of flexibility when using such a tariff and, on the other hand, they only have an environmental impact if they are used in combination with them and if the electricity prices depend on the availability of electricity from renewable resources in the grid.

I can save time, if I don't have to care about the price levels and tariffs myself and coordinate all the consumption. That would be great. (P22-4, male, 47 yrs.)

White goods were seen as the ideal appliances to be exchanged for smart versions because they have high power consumption so their optimized use could lead to substantial monetary savings. Consumer goods that satisfy basic needs such as lighting, cooking, or entertainment, or that are needed at short notice were less likely to be subjected to variable tariffs.

Everything that I can shift is ok, such as the freezer. I guess the TV is a good example of the contrary. I watch the news at eight o'clock and I wouldn't want it to turn off 
automatically due to a higher electricity price. So I don't think that smart technology makes sense for anything other than white goods. (P2-1, male student, 23 yrs.)

A few participants questioned the wisdom of time-of-use tariffs and doubted their ecological effect because smart appliances have to be left on in order to be able to receive signals, e.g., to start a particular washing programme.

I don't believe that it's very efficient. Let's say that I load the washing machine and it has to stay on stand-by for hours until the next low-price level is active. We have been educated to avoid leaving appliances on stand-by. (P5-1, female student, 27 yrs.)

A few non-student participants showed some scepticism regarding the interests of utilities in this technology. Similar to the sceptical reaction concerning the variable tariffs, they were concerned that utilities might be able to influence smart appliances to switch on at expensive times which would be difficult to control or detect.

The question is whether I can trust the utility. If they send the signal to appliances to turn on just $10 \mathrm{~min}$ before the tariff really is in a low-price zone, I wouldn't notice and maybe lose 10 cents. With the number of customers, the danger of manipulating these signals for economic reasons is just too high. (P23-3, male, 48 yrs.)

Still, overall the participants of the non-student groups (groups three and four) arrived at a positive evaluation over the course of the discussion, saying that smart appliances were an appealing concept. Interestingly, when asked individually in the postquestionnaire nearly everybody (23 participants) agreed on liking the idea of having smart appliances at home. However, nobody considered actually replacing their household appliances with smart ones in the near future. There are currently only very few products on the market and therefore their prices, examples were provided by moderator, were rated too high-especially too high when considering the possible payback time. In any case, there was a general consensus among the participants-regardless of their technological orientation-that the acquisition of smart appliances would only be considered if the current appliances stopped working properly.

Wait with the smart dishwasher until the current one breaks down. It doesn't make sense to throw away a functioning dishwasher and buy a smart one instead that costs twice the price. How could I ever conserve that much power afterwards? (P173, female, 51 yrs.)

\section{Home automation}

As a last feature, three different options for managing the household appliances were discussed. Besides the option of manually turning on household appliances according to variable electricity prices (1), there are home automation options, such as the automatic reactions of smart appliances using an EMS as demonstrated in the section above. Apart from the possibility for residents to set their preferences (2), e.g., time when certain devices should run, another option was introduced: allowing a third party - a utility or a demand-side manager - to manage the EMS from outside the home via remote control (3). There are two conceivable versions here: handing over control completely or only at certain times, e.g., only during working hours. Even though only one participant saw advantages for himself in the (time-restricted) remote control option, this option was the most discussed and raised many questions. The main concern expressed by everybodyregardless of age - was the question of data privacy. The participants 
demanded also the possibility to opt out and use the appliances manually, for example, turning on the washing machine when needed regardless of the price level. While financial compensation was appealing for the other technologies, it had no motivational effect for the remote control option.

The remote-control option is not an alternative for psychological reasons because it's strange to feel somehow observed. (P8-2, male student, 24 yrs.)

A home automation system, where the control remains with the residents, was appealing to half the participants, because most of the EMS data, such as the detailed load of each appliance in use, stays under the resident's control and relatively little information is sent to the utility via smart meters, e.g., total load curve, for billing purposes. The main incentive to use an automated system was the higher degree of convenience when it comes to variable tariffs. Issues such as innovativeness and first-mover aspirations did not play a role.

With regard to other household members, home automation options were not rated as positively as the other technologies discussed because of the greater effort needed for coordination regarding, e.g., time preferences for opting out. Other barriers to implement home automation systems included the lack of standards, the general technical complexity and (in the non-student group) the higher power consumption because all the additional components need to be on constant stand-by. So even though some saw advantages for themselves in the automation solutions, nobody was actually planning to retrofit their homes.

\section{Discussion}

Summary and discussion of results

In this study, 29 participants in four focus groups discussed technologies that aim to improve energy efficiency in everyday life. A structured design in a smart home on KIT's campus was used to demonstrate four technical innovations to enable load-shifting as well as electricity savings: variable tariffs, smart metering, smart appliances, and home automation.

The initial reactions towards the demonstrated technologies were positive and participants believed that using the equipment could be advantageous for them. Monetary savings were considered to be the most important benefit. Evaluations became more positive with increasing financial benefits and with shorter payback periods for the smart home equipment. Variable tariff models, especially time-of-use tariffs, were the most popular of the presented technologies because they do not require initial investments in hardware. However, having to change daily routines and/or decrease the degree of individual flexibility in order to adapt to different electricity price levels, as in the case of variable tariffs, limited the willingness for both conserving electricity and shifting loads. Thus, the main barrier to adopting this new technology is the cognitive effort required for changing behavioural patterns. Therefore, most participants would like supplementary solutions that facilitate the use of variable tariffs, such as smart appliances and home automation systems. However, hardly anyone was seriously considering implementing either of these two technical innovations in the near future. In contrast to this, the majority of participants thought a smart meter worth obtaining as soon as more variable tariffs are offered on the market.

The motives for adopting or rejecting smart home technologies abstracted from the results can be broken down to five key drivers: price, convenience, ecology, transparency and technical equipment. These drivers are itemized in Table 1. 
Table 1 Main motives for adopting or refusing smart home technologies

\begin{tabular}{ll}
\hline Main incentives for adoption & Main reasons for refusal \\
\hline - Monetary savings & • Cognitive effort/confirmed habits \\
- Lower ecological footprint & $\bullet$ High expenses \\
- Increased convenience & $\bullet$ Doubts on ecological sense \\
- Higher transparency & $\bullet$ Data privacy protection \\
- Technological orientation & $\bullet$ Technical complexity \\
\hline
\end{tabular}

Bearing the sample structure in mind (interested in energy-related topics, open-minded for new technologies, heterogeneous with regard to state of life, wide spread of age), the analysis of the results is particularly interesting. Even in this sample, the participants had little knowledge about their electricity consumption patterns and, with one exception, nobody was familiar with any of the technologies presented. This reveals again the particularity of electricity and the challenges to be faced when marketing electricity products and services (cf., Hargreaves et al. 2010). The participants were very interested in further information on how to cut electricity costs, which was the main reason underlying the positive evaluation of load visualization using smart meters and in-house displays and which has also been stated in other studies (cf. forsa 2010). However, during the course of the discussions it became clear that applying additional knowledge about electricity consumption in order to achieve a more energy-efficient lifestyle is limited by households' daily habits-even though most participants were aware that saving energy implied changes to their lifestyle as indicated in the prequestionnaire. This barrier was also very relevant for the load-shifting measures. Even though most participants understood about the overall benefits of load-shifting (increased integration of renewable resources, more efficient use of generation capacities) and that this implied flexible demand via dynamic electricity tariffs, less dynamic tariffs were still generally preferred. As long as the individual benefits are thus not directly perceivable it will be difficult to achieve a broad acceptance of "smart" electricity tariffs. Technical solutions, such as smart appliances, that could help to automate energy consumption decisions and cope with dynamic tariffs were therefore welcomed-as long as they did not interfere with daily routines and were reliable regarding operation and safe data handling. The innovativeness of such options was not the key driver for their acceptance-regardless of the participant's technical orientation. They must offer other benefits that match the consumers' desire to get easy and simple advice on how to save electricity costs. Greater transparency about consumption and costs can satisfy information requirements in the short run and be a good starting point for offering attractive solutions. As in the case of smart meters, our study shows that supplementary applications will have to be integrated in order to satisfy consumer needs in the long run.

Some implications for policy making can be drawn from our study. Current European and national policies which promote the introduction of smart meters aim to provide consumers with more information and expect them to live more energy-efficiently as a result of that knowledge. The results of our study question many of the assumptions underlying these policies, including the German Energy Act: The diffusion of smart meters may not depend so much on their technical attractiveness as on their economics. The participants of our study expected to receive a smart meter for free or at least for a price which implies a very short payback time. This in turn implies that smart meters must offer a sufficient saving potential.

Concerning this point the German Energy Act assumes that savings are possible, if enough information on electricity consumption is provided to the households, as they will consequently conserve electricity and thus save money. Our study revealed two problems: 
While there was the desire for more information among the participants, they were not satisfied with the level of detail provided by the smart meter. Indeed, the German Energy Act does not specify the data to be provided by a smart meter in sufficient detail. Current solutions provide only the total load in a household. According to our study, more detailed information is required, such as breaking the load down to the level of specific appliances or rooms within a house. Apart from insufficient information, our results also suggest another problem: Smart meters can lead to savings in the short term if consumers are able to detect electricity guzzlers and conserve power by using these devices less, but this effect is limited for various reasons that lie within the households. Information about electricity consumption is not expected by our informants to become applied directly in electricity-conserving solutions, especially if this requires changes in daily patterns of behaviour. Furthermore, smart meters alone are hardly an incentive for load-shifting unless they are accompanied by variable tariffs. Their cost-saving potentials depend not only on the price spread, but also on the willingness of households to choose such a tariff as well as to shift much of their consumption to low-priced time zones. Again, this can only be expected if saving potentials are high enough and tariff structures are easily manageable in everyday life.

Another barrier that has not been sufficiently addressed by policymakers so far is the mistrust in utilities. In our study, it was a point of discussion across all groups with every technology-and included concerns about the correct calculation of electricity prices, possibilities to opt out of the "smart system", and the proper use of private data. An amendment of the German Energy Act ( $\S 21 \mathrm{~g}, 21 \mathrm{~h})$, that has passed parliament, defines technical criteria for the (smart) meter itself (such as the requirement of certain protocols), but it lacks clear security guidelines for handling the meter data. This policy relies on the trustworthiness of the market player (utility, network or metering operator) that will read the meters. Neither other technical features of a smart home nor specific consumer rights have found their way into policies yet, although some ideas - such as the consumer's right to lock or delete data-are being discussed (Raabe et al. 2011).

In sum, national policy does currently not sufficiently take into account the behavioural aspects that go beyond information needs and it neglects many of the motives and barriers affecting the individual decision-making process, even though they are decisive for the diffusion of smart technologies and therefore of our progression towards a low-carbon society.

\section{Limitations}

As with all empirical work, this study is subject to several limitations. Certainly, the generalizability of the findings is limited. The sample recruited for this study is not representative for any kind of population-younger adults with a high level of education are overrepresented. Moreover, participants were recruited after they had volunteered, i.e., they were not recruited using a random approach. Thus, individuals not interested in this kind of technology development as well as those with strong reservations were probably not represented in the groups and their views are therefore not covered in our study. However, when recruiting participants for the focus groups we deliberately tried to engage individuals who are likely to be among those who first embrace smart home technologies. Moreover, while the KIT's smart home offered a unique chance of illustrating the possibilities offered by such an environment, this is also a limitation because smart home environments that are designed differently may also elicit different reactions. 


\section{Conclusions}

Our study sheds light on the reasons for adopting or rejecting smart home technologies. It turns out that, besides the central incentive of saving money, environmental-friendliness, high levels of flexibility, greater transparency about electricity consumption and costs as well as enthusiasm for new technologies are all factors which are likely to play a motivational role. At the same time several reasons, such as confirmed habits in daily life and costly investments, might lead to refusal. Since variable tariffs were thought to be the most attractive solution in this study, further analysis of consumers' preferences regarding the different types of variable tariffs as well as regarding the actual effect of such tariffs on household electricity consumption over a longer period of time seem worthwhile. In order to challenge this study's results in everyday life, further research on the attitudinal and behavioural effects of living in such a smart home is needed.

Based on the results of this study, we recommend that policies and industry should design integrated offers in order to support the market entrance of energy-related smart home technologies. Using an open innovation approach, which integrates consumer experiences, e.g., from the various field tests, into the product design process, could further help to offer market solutions that satisfy the consumers' needs for convenience, transparency and usability. These needs are currently not being met by any single technology. Combining smart meters-for their transparency-with variable tariffs-for their cost-saving potential-and smart appliances-for their usability-was the most preferred option in this study.

All I wish for is a simple structured variable tariff maybe with a smart meter. As soon as the tariff gets complex, I need smart appliances otherwise I wouldn't be able to shift my consumption according to the price levels. And it has to be user-friendly without an engineering approach. (P29-4, male 47 yrs.)

Acknowledgements This research was made possible as a part of the project MeRegioMobil, which is funded by the German Federal Ministry of Economics and Technology (Grant 01ME09005).

\section{References}

Allen, D., \& Janda, K. (2006). The effect of household characteristics and energy use consciousness on the effectiveness of real-time energy use feedback: A pilot study. Proceedings of the ACEEE 2006 Summer Study on Energy Efficiency in Buildings, 1-12.

Bergstein, H., \& Estelani, H. (2002). A survey of emerging technologies for pricing new-to-the world products. The Journal of Product and Brand Management, 11, 303-318.

Birzle-Harder, B.,Deffner, J., \& Götz, K. (2008). Lust am Sparen oder totale Kontrolle? Akzeptanz von Stromverbrauchs-Feedback. Report. Can be ordered from URL: http://www.shop.isoe.de.

BMWi. (2011). Eckpunkte für ein energiepolitisches Konzept. Report of the German Federal Ministry of Economics and Technology. URL: http://www.bmwi.de/BMWi/Navigation/Energie/Energiepolitik/ energiekonzept,did=405004.html (06/06/2011).

Bryman, A. (2001). Social research methods. New York: Oxford University Press.

Darby, S. (2010). Smart metering: What potential for householder engagement? Building Research and Information, 38, 442-457.

IBM Global Business Services, \& Zentrum für Evaluation und Methoden der Universität Bonn. (2007). Preis, Verbrauch und Umwelt versus Komfort-der mündige Energieverbraucher. Verbrauchsverhalten und neue Möglichkeiten zur Kundenbindung und Kundengewinnung für Energieversorger. Report. URL: http://www-05.ibm.com/de/pressroom/downloads/energie-studie.pdf (28/01/11). 
Energate. (2011). Daily News, Energate Messenger N 119, 22.06.2011.

SF-Sustainability First and Engage Consulting Limited. (2008). International Smart Meter Trial Selected Case Studies Smart Tariffs and Customer Stimuli. Report. URL: http://www.sustainabilityfirst.org.uk/ publications.htm (28/01/11).

Faruqui, A., Harris, D., \& Hledik, R. (2010). Unlocking the $€ 52$ billion savings from smart meters in the EU. Energy Policy, 38, 6222-6231.

Fischer, C. (2007). Influencing electricity consumption via consumer feedback: a review of experience. Proceedings ECEEE 2007 Summer Study, 1873-1884.

forsa. (2010). Erfolgsfaktoren von Smart Metering aus Verbrauchersicht. Report.URL: http://www.vzbv.de/ mediapics/smart_metering_studie_05_2010.pdf.

Grønhøj, A., \& Thøgersen, J. (2011). Feedback on household electricity consumption: Learning and social influence processes. International Journal of Consumer Studies, 35, 138-145.

Hargreaves, T., Nye, M., \& Burgess, J. (2010). Making energy visible: A qualitative field study of how householders interact with feedback from smart energy monitors. Energy Policy, 38, 6111-6119.

Heberlein, K., \& Warriner, G. K. (1983). The influence of price and attitude on shifting residential electricity consumption from on-to off-peak periods. Journal of Economic Psychology, 4, 107-130.

Kuckartz, U., Dresing, T., Rädiker, S., \& Stefer, C. (2007). Qualitative evaluation. Wiesbaden: VS Verlag für Sozialwissenschaften.

Mayring, P. (2000). Qualitative Content Analysis. Forum: Qualitative Social Research, 1 (2).

Mert, W., Watts, M., \& Tritthart, W. (2009). Smart domestic appliances in sustainable energy systemsConsumer acceptance and restrictions. Proceedings of the ECEEE 2009 Summer Study, 1751-1761.

Pyrko, J. (2011). Am I as smart as my smart meter is?-Swedish experience of statistics feedback to households. Proceedings of the ECEEE 2011 Summer Study, 1837-1841.

Raabe, O., Lorenz, M., Pallas, F., Weis, E., \& Malina, A. (2011). 14 Thesen zum Datenschutz im Smart Grid. Datenschutz und Datensicherheit, 08(2011), 519-523.

Schleich, J., Klobasa, M., Goelz, S., \& Götz, K. (2011).Smart metering in Germany-Results of providing feedback information in a field trial. Proceedings of the ECEEE 2011 Summer Study, 1667-1674.

UBA. (2011).CO2-Emissionen nach Quellkategorien. Bericht des Umweltbundesamtes. Report. URL: http:// www.umweltbundesamt-daten-zur-umwelt.de/umweltdaten/public/theme.do?nodeIdent=2842 (29/01/ 11).

Van Dam, S. S., Bakker, C. A., \& Van Hal, J. D. M. (2010). Home energy monitors: Impact over the medium term. Building Research \& Information, 38, 458-469.

Van Westendorp, P. (1976). NSS-price sensitivity meter (PSM). A new approach to study consumer perception of price. Proceedings of the 29th ESOMAR Congress, 139-167. 